\title{
Aplikasi Pembelajaran Alfanumerik Untuk Anak Usia Pra-Sekolah Berbasis Android Menggunakan Metode Tesseract-Ocr
}

\author{
(Alphanumeric Learning Application for Android-Based Pre-School Children Using \\ the Tesseract-Ocr Method)
}

\author{
Darmawan Aditama, Harunur Rosyid, Nuniek Fahriani ${ }^{1}$ \\ Prodi. Teknik Informatika, Fakultas Teknik, Universitas Muhammadiyah Gresik \\ Jl. Sumatera No.101, Gn. Malang, Randuagung, Kec. Gresik, Kabupaten Gresik, Jawa Timur 61121 \\ Email: awanaditama@umg.ac.id, harun@umg.ac.id,nuniekfahriani@umg.ac.id
}

\begin{abstract}
Alphanumeric writing ability is the main provision for children to be able to understand the subjects given in school. One alternative to help increase children's interest and ability in learning to write Alphanumeric is to use learning media in the form of software. This study is to create an application that presents Alphanumeric writing learning that is intentionally packaged in the form of a game in order to increase the learning interest of pre-school age children. In this study used the method of recognition of character letters made by the player. In character recognition, the application will record the handwriting that the user has created on the board provided. The handwriting will then be used at the image processing stage that uses Tesseract as the recognition engine. And from the results of the trials, pre-school children easily manage it.
\end{abstract}

Key words: Alphanumeric, Writing, Android, Learning, Tesseract-Ocr

\section{PENDAhULUAN}

Kemampuan menulis alfanumerik merupakan bekal utama bagi anak untuk dapat memahami mata pelajaran yang diberikan di sekolah. Salah satu alternatif untuk membantu meningkatkan minat dan kemampuan anak dalam belajar menulis alfanumerik dengan menggunakan media pembelajaran berupa perangkat lunak (software).

Android merupakan perangkat lunak yang dipilih, dengan alasan android banyak digunakan pada perangkat mobile seperti smartphone, hal ini menjadi alasan tambahan mengapa android dipilih sebagai media untuk membangun aplikasi ini.

Penelitian ini bertujuan untuk membuat sebuah aplikasi yang menyajikan pembelajaran menulis alfanumerik yang sengaja dikemas dalam bentuk permainan supaya dapat meningkatkan minat belajar anak usia pra-sekolah.

Dengan perkembangan teknologi saat ini, pemanfaatan teknologi yang baik akan sangat membantu untuk memberikan pembelajaran kepada anak-anak. Teknologi yang dirancang dan dikonsep sedemikian rupa akan sangat menarik minat anak-anak untuk menggunakannya. Anakanak di era modern sangat tertarik dengan game, dengan konsep yang baik maka kita seharusnya dapat memanfaatkan peluang dalam game tersebut. Dengan menyisipkan nilai atau manfaat pembelajaran di dalamnya kita sudah bisa memberikan hiburan sekaligus pendidikan yang secara tidak langsung dapat membangun anak-anak kita.

Media pembelajaran bisa berupa apa saja, dan dengan perangkat mobile, sebuah konsep pembelajaran menulis alfanumerik dibangun dengan tujuan memberikan hiburan dan pengetahuan kepada anak-anak menggunakan sistem operasi Android. Android merupakan platform sistem operasi perangkat mobile milik Google, sistem tersebut secara bebas dapat dikembangkan oleh orang banyak, atau kita kenal dengan istilah open source.

Android terpasang pada perangkat mobile yang biasa kita sebut pula dengan smartphone dan tablet. Perangkat ini akan sangat sesuai dengan aplikasi media pembelajaran di mana target utama pengguna yang menggunakan aplikasi tersebut adalah anak-anak. Dengan layar sentuh akan sangat menarik untuk anak-anak membentuk karakter alfanumerik, sehingga mereka dapat langsung menerapkan hasil belajar mereka pada perangkat itu juga.

Aplikasi pembelajaran ini dibagi menjadi dua pengenalan, yaitu pengenalan pola dan pengenalan karakter. Untuk pengenalan polanya, dibuat menggunakan citra yang didasari dari metode pattern agar garis yang dibuat tidak putus meskipun jari digerakkan ke segala arah. Di dalamnya juga disediakan bola yang akan menuntun pengguna dalam menulis alfanumerik tanpa kehilangan kaidah penulisan yang berlaku di pendidikan.

Sedangkan dalam melakukan pencocokan bentuk karakter, aplikasi akan merekam tulisan tangan yang telah dibuat oleh pengguna pada papan yang disediakan. Tulisan tangan tersebut kemudian akan digunakan pada tahapan pengolahan citra yang menggunakan Tesseract sebagai mesin pengenalannya. 


\section{TINJAUAN PUSTAKA}

\section{A. Penelitian Sebelumnya}

Penelitian sebelumnya telah dilakukan oleh Susana Limanto pada tahun 2002 dalam Tugas Akhir yang berjudul "Peningkatan Minat Dan Kemampuan Anak Usia Pra-sekolah Untuk Belajar Membaca Dan Menulis Permulaan Menggunakan Komputer Aided Learning". Fokus penelitian ini adalah membuat sebuah aplikasi berbasis komputer yang dapat menyampaikan materi dengan cara yang menarik (melalui gambar, lagu, cerita dan suara) yang dapat membantu siswa belajar membaca dan menulis dengan lancar [1].

Pada penelitian yang dilakukan oleh Hilda Karli pada tahun 2010 dalam jurnal pendidikan yang berjudul "Membaca dan Menulis untuk Anak Usia Dini melalui Aktivitas dan Permainan yang Menyenangkan". Pada penelitian tersebut diketahui bahwa media pembelajaran yang dipadukan dengan gambar dan permainan dapat menghilangkan kejenuhan pada anak [2].

Penelitian mobile game yang dilakukan oleh Heru Prayogo pada tahun 2013 dalam skripsi Universitas Trunojoyo Madura yang berjudul "Rancang Bangun Aplikasi Media Pembelajaran Alphabet Untuk Perangkat Mobile Android". Dalam penelitian tersebut, dia menggunakan smartphone berbasis Android untuk membuat game belajar menulis alphabet [3].

\section{B. Pengertian Aplikasi}

Menurut Dhanta pada bukunya tahun 2009 yang berjudul "Pengantar Ilmu Kompter", aplikasi (application) adalah software yang dibuat oleh suatu perusahaan komputer untuk mengerjakan tugas-tugas tertentu, misalnya Microsoft Word, Microsoft Excel[4]. Sedangkan menurut Anisyah pada bukunya tahun 2000 yang berjudul "Analisa dan Desain Sistem Informasi", aplikasi adalah penerapan, penggunaan atau penambahan[5].

Dari pengertian di atas, dapat disimpulkan bahwa aplikasi merupakan software yang berfungsi untuk melakukan berbagai bentuk pekerjaan atau tugas-tugas tertentu seperti penerapan, penggunaan dan penambahan data.

\section{Aplikasi Mobile Berbasis Android}

\section{C.1.Pembuatan karakter}

Perangkat mobile saat ini merupakan perangkat yang banyak digunakan oleh anak-anak. Dengan komunikasi interaktif melalui layar sentuh yang menarik, smartphone android memberikan peluang yang lebih besar untuk mengembangkan aplikasi media pembelajaran yang lebih baik.

\section{C.2. Android}

Android adalah sebuah sistem operasi untuk perangkat mobile berbasis Linux yang mencakup sistem operasi, middleware dan aplikasi. Android menyediakan platform yang terbuka bagi para pengembang untuk menciptakan aplikasi mereka. Awalnya, Google Inc. membeli Android
Inc. yang merupakan pendatang baru yang membuat peranti lunak untuk ponsel/smartphone. Kemudian untuk mengembangkan Android, dibentuklah Open Handset Aliance yang merupakan konsorsium dari 34 perusahaan peranti keras, peranti lunak, dan telekomunikasi, termasuk Google, HTC, Intel, Motorola, Qualcomm, T-Mobile, dan Nvidia.

\section{C.3. Eclipse}

Eclipse adalah sebuah IDE (Integrated Development Environment) untuk mengembangkan perangkat lunak dan dapat dijalankan di semua platform (platform-independent) [6]. Berikut ini adalah fasilitas dari Eclipse:

1) Multi-platform: Target sistem operasi Eclipse adalah Microsoft Windows, Linux, Solaris, AIX, HP-UX dan Mac OS X.

2) Multi-language: Eclipse dikembangkan dengan bahasa pemrograman Java, akan tetapi Eclipse mendukung pengembangan aplikasi berbasis bahasa pemrograman lainnya, seperti $\mathrm{C} / \mathrm{C}++$, Cobol, Python, Perl, PHP, dan lain sebagainya.

3) Multi-role: Selain sebagai IDE untuk pengembangan aplikasi, Eclipse pun bisa digunakan untuk aktivitas dalam siklus pengembangan perangkat lunak, seperti dokumentasi, test perangkat lunak, pengembangan web, dan lain sebagainya.

\section{C.4. SDK}

Android SDK adalah software yang memungkinkan pengembang untuk membuat aplikasi untuk Android. Android SDK mencakup contoh proyek dengan menyertakan source code, alat pengembang, emulator dan library yang dibutuhkan untuk membangun aplikasi Android. Aplikasi di tulis menggunakan bahasa pemrograman Java dan berjalan di Dalvik virtual machine, yaitu mesin virtual yang di bangun khusus untuk pengembangan Android [7].

\section{Anak Usia Pra-Sekolah}

Masa anak usia dini disebut juga sebagai masa awal anak-anak yang memiliki berbagai karakter atau ciri-ciri. Ciri-ciri ini tercermin dalam sebutan-sebutan yang diberikan oleh para orang tua, pendidik, dan ahli psikologi untuk anak usia dini. Bagi orang tua, masa awal anak-anak merupakan usia yang sulit, karena anak-anak berada dalam proses pengembangan kepribadian.

Masa awal anak-anak juga disebut sebagai usia prasekolah. Sebutan ini diberikan untuk membedakan antara anak-anak yang berada dalam pendidikan formal dan yang belum. Oleh karena itu, tekanan yang diberikan untuk anak pra-sekolah juga berbeda dari anak-anak yang sudah sekolah, yaitu bahwa usia pra-sekolah merupakan usia persiapan menuju sekolah formal.

Usia dini juga disebut sebagai usia menjelajah atau usia bertanya. Ini dikarenakan pada usia dini mereka dalam tahap ingin tahu keadaan lingkungannya, bagaimana 
mekanismenya, bagaimana perasaannya serta bagaimana supaya anak dapat menjadi bagian dari lingkungannya. Selain itu anak usia dini juga disebut sebagai usia meniru. Anak-anak meniru pembicaraan dan tingkah laku orang lain.

Namun demikian, anak-anak juga sering kedapatan menunjukkan kreativitas mereka dalam bermain pada usia ini. Oleh karena itu masa ini juga disebut usia kreatif.

Usia lima tahun pertama adalah masa emas untuk perkembangan anak, karena pada usia ini anak mengalami masa peka dan kritis. Masa peka (sensitive period), merupakan periode di mana anak telah mencapai kesiapan untuk belajar. Betapa pun banyaknya rangsangan yang diterima anak, mereka tidak dapat belajar sampai perkembangan mereka siap untuk melakukannya.

Hal ini berarti bahwa belajar sesuatu akan lebih dapat dilaksanakan bila kematangan anak telah tiba. Bila anak belum mencapai masa peka, upaya mengajar mereka hanyalah membuang-buang waktu dan tidak ada gunanya, bahkan akan menimbulkan perilaku yang tidak diinginkan, misalnya menimbulkan kejenuhan atau keengganan untuk belajar. Sebaliknya, jika anak telah siap untuk belajar tetapi tidak mendapatkan kesempatan atau dorongan untuk melakukannya, maka minat mereka akan hilang.

Pada fase anak usia dini, karakteristik anak dapat dikategorikan berdasarkan tahap-tahap perkembangan. Berkaitan dengan aspek sosial emosi, masa anak usia dini dibagi dalam tiga periode perkembangan, yaitu [8]:

1) Masa bayi (usia $0-18$ bulan), sebagai tahap terbentuknya kepercayaan dasar, dengan karakteristik berupa adanya kebutuhan dasar bayi yang harus dipenuhi oleh pengasuh yang tanggap dan peka agar terbentuk rasa kepercayaan yang akan menimbulkan rasa aman.

2) Masa toddlers (usia 18 bulan - 3 tahun), sebagai tahap terbentuknya kemandirian, dengan karakteristik berupa adanya kemauan yang berasal dari diri sendiri, sehingga bayi mulai mengembangkan rasa kemandiriannya.

3) Masa awal anak-anak (usia 3 - 6 tahun), sebagai tahap terbentuknya inisiatif dengan karakteristik anak yang mulai mengembangkan berbagai aktivitas dan perilaku yang lebih bertujuan. Lingkungan yang memberi kesempatan bereksplorasi akan dapat mengembangkan kemampuan anak untuk menerima tanggung jawab, aktif, dan memiliki keterlibatan dengan lingkungan.

Sedangkan menurut Piaget menjelaskan bahwa perkembangan kognitif pada anak usia pra-sekolah terdiri dari empat tahapan yang terdiri dari tahapan sensorimotor, tahapan pra-operasional, tahapan kongkret operasional dan tahapan formal operasional. Beberapa ciri - ciri perkembangan kognitif pada anak pra-sekolah adalah sebagai berikut [9].

Ketika anak-anak memiliki atau tidak memiliki pengalaman literasi sejak dini, seperti dibacakan secara teratur, keberhasilan mereka selanjutnya dalam belajar membaca sangat dipengaruhi oleh hal tersebut. Mungkin yang paling meyakinkan adalah hasil-hasil penelitian yang menunjukkan bahwa pengalaman-pengalaman sosial dan sensorik motorik selama tiga tahun pertama kehidupan secara langsung mempengaruhi perkembangan neurologis otak, dengan implikasi-implikasi penting dan menetap terhadap kapasitas-kapasitas anak untuk belajar.

\section{METODE PENELITIAN}

\section{A. Metode Penelitian}

\section{A.1 Sistem Pengenalan Pada Karakter}

Pada bagian pengenalan karakter menggunakan library tesseract dan tess-two, di mana masukan dari pengguna berupa tulisan tangan dari alfanumerik akan dicocokkan dengan data training yang kemudian menunjukkan apakah tulisan tersebut sudah benar atau belum benar.

\section{A.2 Pembuatan Karakter}

Pembuatan karakter dilakukan pada perangkat mobile. Pembuatan karakter memanfaatkan layar sentuh perangkat untuk membuat karakter alphabet oleh pengguna.

Pada gambar 1 menunjukkan cara melakukan pembuatan karakter yang dicontohkan dengan membuat alphabet "A".

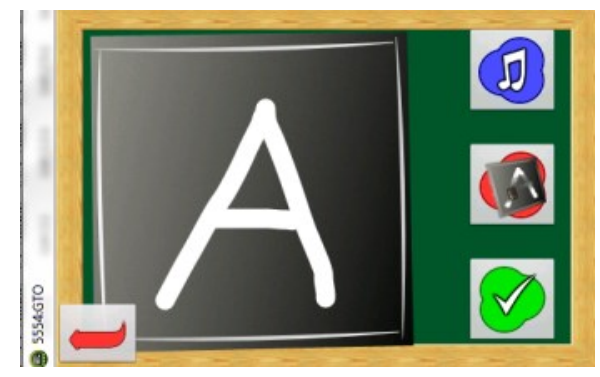

Gambar 1. Contoh Membuat Karakter Alphabet

Pada gambar 2 menunjukkan cara melakukan pembuatan karakter yang dicontohkan dengan membuat numerik"1".

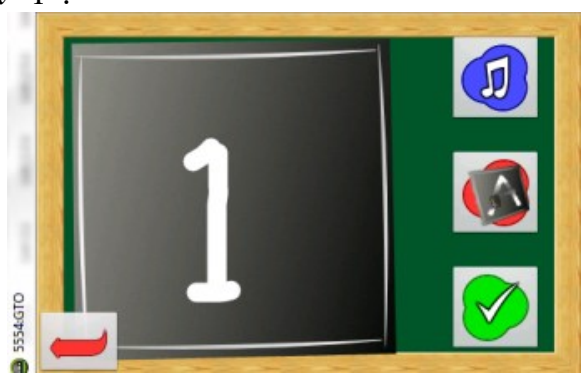

Gambar 2. Contoh Membuat Karakter Numerik

\section{A.3 Pengenalan karakter}

Setelah karakter berhasil dibuat, akan disimpan menjadi sebuah citra dengan ukuran yang telah disesuaikan pada canvas. Gambar berupa tulisan warna putih di atas latar hitam yang disimpan dalam bentuk JPEG. Pengenalan karakter kemudian dilakukan oleh Tesseract OCR. 
Seperti yang dijelaskan pada referensi bahwa dalam melakukan pengenalan pola, dilakukan banyak proses awal yang disebut preprocessing. Preprocessing bisa berupa proses thresholding. Namun karena masukan dari aplikasi ini sudah dirancang sebagai gambar biner, maka tidak diperlukan lagi proses tersebut. Selain proses thresholding, ada juga proses pemotongan atau cropping lalu mengubah skala gambar. Selain itu, ada pula deteksi tepi dan lain sebagainya.

Namun karena untuk pengenalan polanya sendiri, digunakan Tesseract maka tidak diperlukan lagi preprocessing seperti yang dikemukakan di atas.

\section{HASIL DAN PEMBAHASAN}

\section{A. Hasil Uji Coba}

Untuk mengetahui hasil dari setiap alphabet \& numerik maka di bawah ini adalah tabel uji coba dari pengenalan pola dan pengenalan karakter dari masing-masing alphabet \& numerik dengan memakai handphone Sony Xperia Go ST21i dengan resolusi 320X480.

\section{B. Tabel Uji Coba}

Uji coba aplikasi terhadap pengguna mengikutsertakan 2 kelas (30 pengguna) TK Aisyiyah di Desa Payaman Kecamatan Solokuro Kabupaten Lamongan. Pada Tabel I sampai dengan Tabel II berikut merupakan contoh hasil percobaan yang dilakukan pada perangkat Sony Xperia Go ST21i yang mengikutsertakan salah seorang anak usia dini agar diketahui apakah aplikasi ini bisa tepat sasaran. Tabel ini tidak mewakili pengguna secara keseluruhan.

TABEL I. TABel Contoh Uji Coba Menulis Alphabet Dengan PENGENALAN KARAKTER

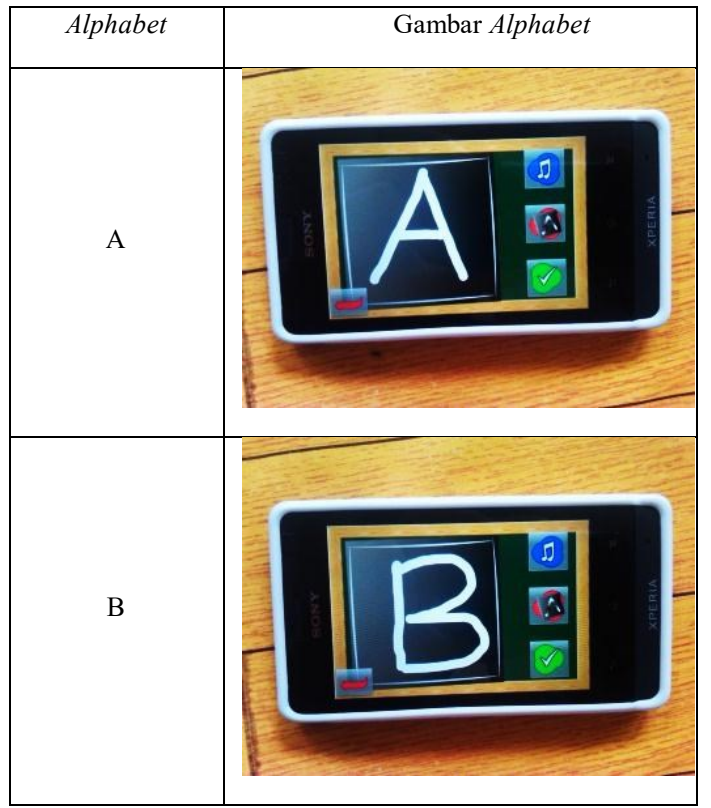

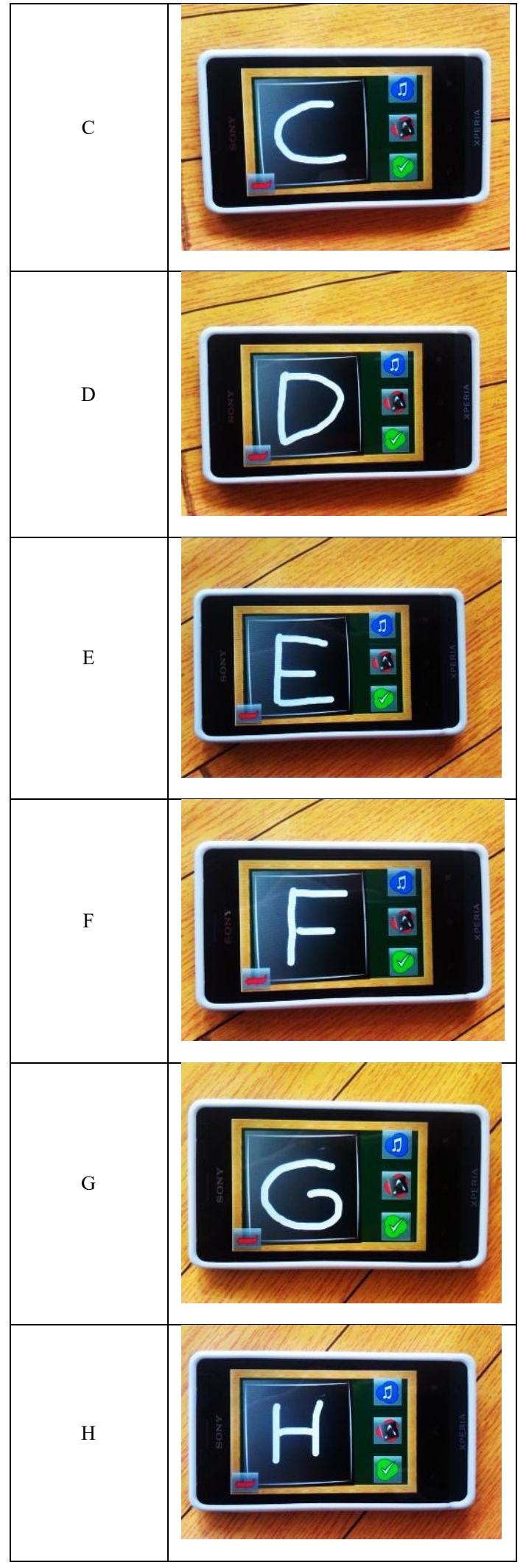



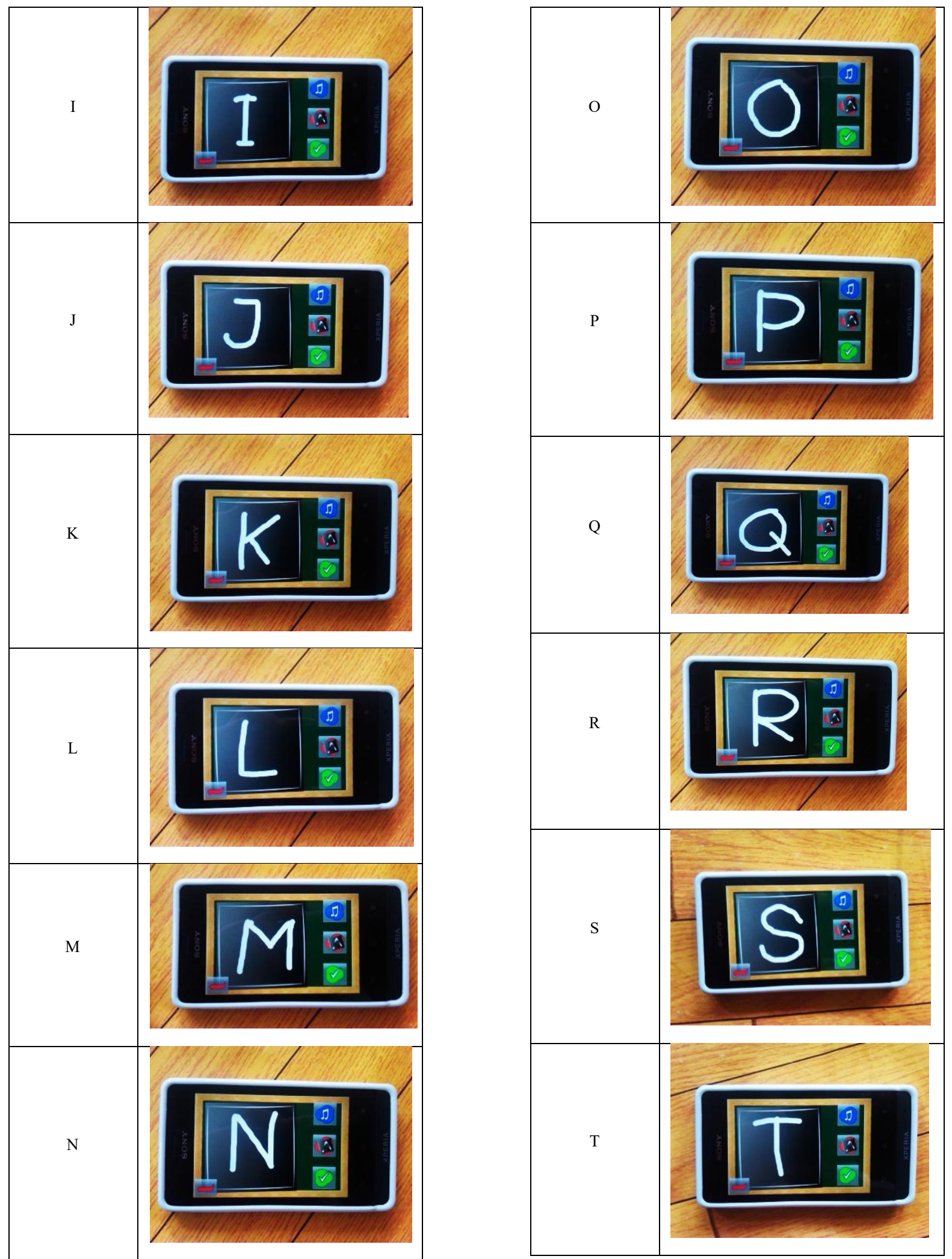


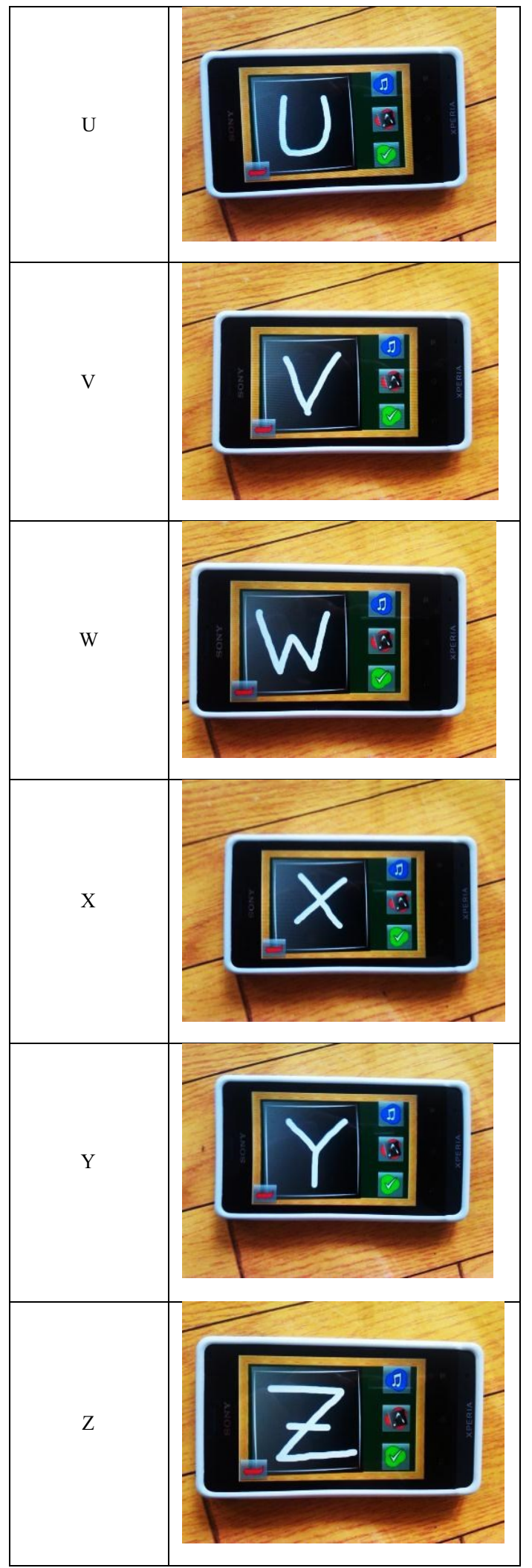

Pada Tabel I dapat disimpulkan bahwa rata-rata pengguna menulis alphabet hanya memerlukan 2 kali percobaan, karena dari dua kelas TK Aisyiyah telah terbiasa menulis alphabet dikertas sebagai dasar pelajaran yang diberikan, bahkan kebanyakan siswa TK Aisyiyah telah hafal alphabet. Disamping itu dalam menulis alphabet pada pengenalan karakter ini, pengguna diizinkan menulis alphabet dari depan maupun dari belakang. Asalkan masih dalam bentuk alphabet yang dapat dikenali oleh library Tesseract-Ocr.

TABEL II. TABEL CONTOH UJi COBA MENULIS NUMERIK DENGAN PENGENALAN KARAKTER

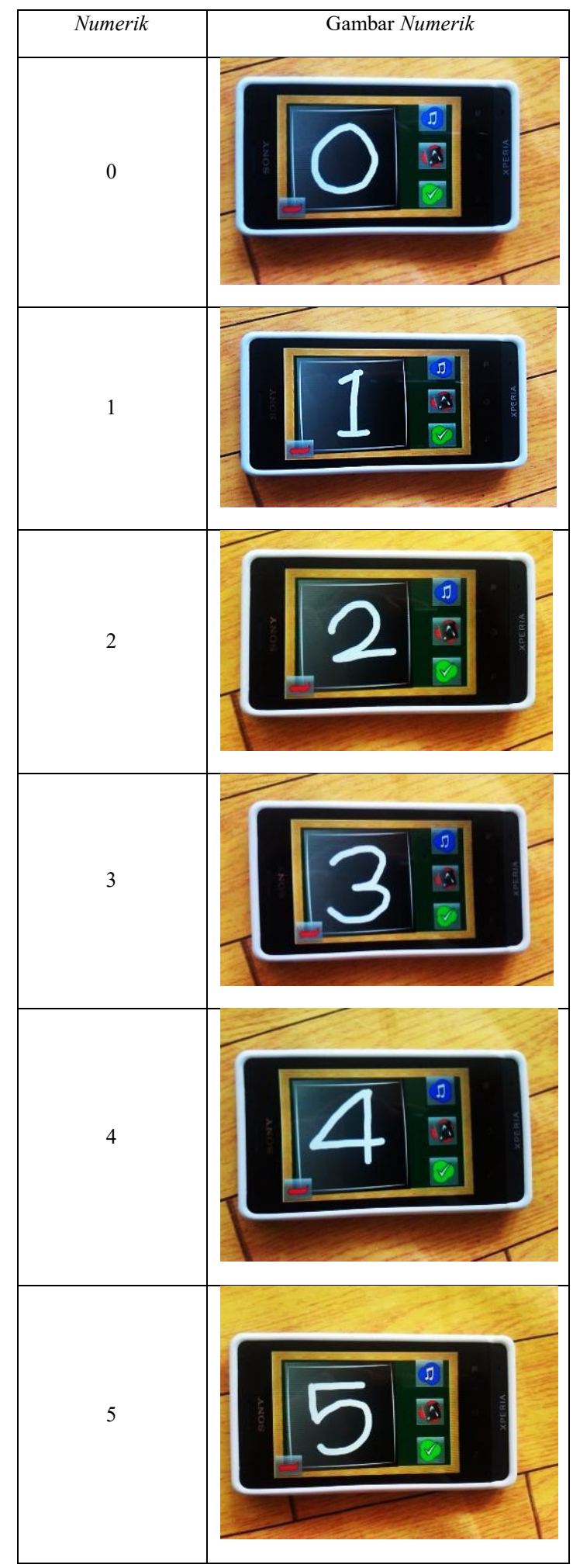




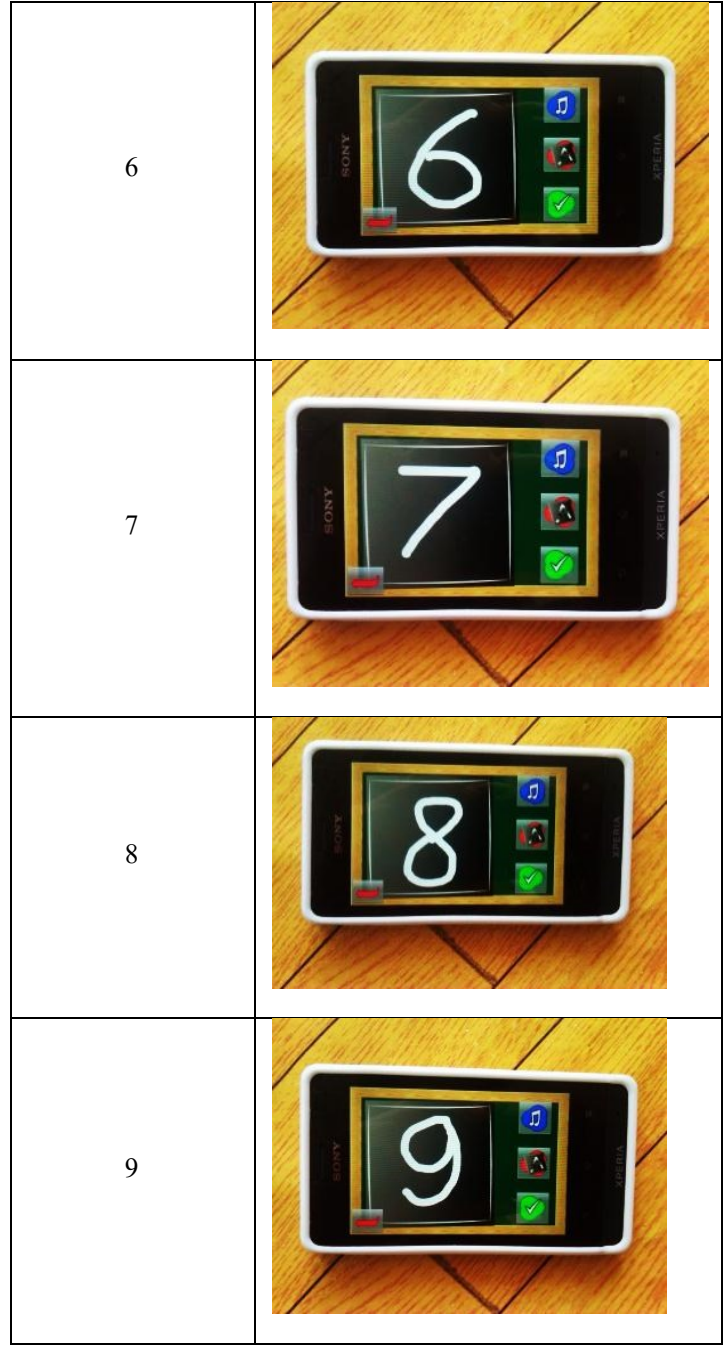

Pada Tabel II dapat disimpulkan bahwa rata-rata pengguna menulis numeric memerlukan 3 kali percobaan, lebih banyak dari saat mencoba menulis alphabet. karena dari dua kelas TK Aisyiyah masih belum terbiasa menulis numeric sehingga pada beberapa numeric siswa didik TK Aisyiyah masih kesulitan menuliskannya. Tidak seperti penulisan alphabet yang penulisannya cukup mudah dan sudah dikuasai oleh siswa TK Aisyiyah. Meskipun dalam menulis numeric pada pengenalan karakter ini, pengguna diizinkan numeric dari depan maupun dari belakang.
Asalkan masih dalam bentuk numeric yang dapat dikenali oleh library Tesseract-Ocr.

\section{KESIMPULAN}

Dari hasil pengujian dan analisa pada bab sebelumnya maka diambil kesimpulan

1. Tesseract dengan bantuan library Tess-two dapat mengenali tulisan tangan dengan bentuk alphabet kapital dan numeric yang ditulis oleh pengguna aplikasi.

2. Aplikasi dapat berjalan dengan baik pada smartphone android yang memiliki resolusi HVGA (320X480 Pixels).

3. Aplikasi juga masih berjalan dengan baik meskipun memakai smartphone android dengan resolusi yang lebih kecil dari HVGA (320X480 Pixels)

4. Namun aplikasi tidak berjalan dengan baik pada smartphone android yang memilik resolusi lebih besar dari HVGA (320X480 Pixels), sehingga masih perlu dikembangkan lagi untuk dapat dijalankan pada smartphone android dengan resolusi yang lebih besar.

\section{DAFTAR PUSTAKA}

[1] L. Susana, Peningkatan Minat Dan Kemampuan Anak Usia Pra-sekolah Untuk Belajar Menulis huruf Permulaan Menggunakan Komputer Aided Learning. Surabaya: Jurusan Teknik Informatika Universitas Surabaya, 2002.

[2] K. Hilda, Membaca dan Menulis untuk Anak Usia Dini melalui Aktivitas dan Permainan yang Menyenangkan. Jakarta: Universitas Katolik Atma Jaya Jakarta, 2010.

[3] H. Prayogo, Rancang Bangun Aplikasi Media Pembelajaran Alphabet Untuk Perangkat Mobile Androi. Madura: Universitas Trunojoyo Madura, 2013.

[4] R. Dhanta, Pengantar Ilmu Kompter. Surabaya: INDAH, 2009.

[5] Anisyah, Analisa dan Desain Sistem Informasi. Yogyakarta:Penerbit Andi, 2000.

[6] T.E. Luthfi, Modul android $1 \& 2 \& 3 \& 4 \& 5.2012$.

[7] D. F. N. Rohmah. Modul Pemrograman Aplikasi Android. 2012.

[8] I. N. Kurniawan. "Prinsip-prinsip Perkembangan Anak"

[9] P. Soemiarti, Pendidikan Anak Pra-sekolah. Jakarta : PT. Rineka Cipta. 2003. 